\title{
Antarctophthirus microchir infestation in synanthropic South American sea lion (Otaria flavescens) males diagnosed by a novel non-invasive method
}

\author{
David Ebmer $^{1}$ (D) Maria José Navarrete ${ }^{2} \cdot$ Pamela Muñoz $^{2} \cdot$ Luis Miguel Flores $^{2} \cdot$ Ulrich Gärtner $^{3} \cdot$ Anja Taubert $^{1}$. \\ Carlos Hermosilla ${ }^{1}$
}

Received: 29 December 2018 / Accepted: 18 February 2019 /Published online: 14 March 2019

(C) The Author(s) 2019

\begin{abstract}
Antarctophthirus microchir is a sucking louse species belonging to the family Echinophthiriidae and has been reported to parasitize all species of the subfamily Otariinae, the sea lions. Former studies on this ectoparasite mainly required fixation, immobilization, or death of host species and especially examinations of adult male sea lions are still very rare. Between March and May 2018, adult individuals of a unique "urban" bachelor group of South American sea lions (Otaria flavescens) living directly in the city of Valdivia, Chile, were studied regarding their ectoparasite infestation status. For first time, a non-invasive method in the form of a lice comb screwed on a telescopic rod and grounded with adhesive tape was used for sample taking process. Overall, during combing different stages of $A$. microchir were detected in 4/5 O. flavescens individuals, especially at the junction between the back and hind flippers. Our findings represent the first report of $A$. microchir infesting individuals of this synanthropic colony and fulfilling complete life cycle in a sea lion group despite inhabiting freshwater and in absence of females/ pups. Our "telescopic lice comb apparatus" offers a new strategy to collect different stages of ectoparasites and a range of epidermal material, such as fur coat hair and superficial skin tissue for a broad spectrum of research fields in wildlife sciences in an unmolested and stress reduced manner.
\end{abstract}

Keywords Echinophthiriidae $\cdot$ Synanthropy $\cdot$ Urban sea lions $\cdot$ Non-invasive sampling

\section{Introduction}

Antarctophthirus microchir is a member of the family Echinophthiriidae belonging to the suborder Anoplura, the

Section Editor: Boris R. Krasnov

Electronic supplementary material The online version of this article (https://doi.org/10.1007/s00436-019-06273-2) contains supplementary material, which is available to authorized users.

David Ebmer

david.ebmer@gmx.at

1 Institute of Parasitology, Biomedical Research Center Seltersberg (BFS), Justus Liebig University Giessen, Schubertstr. 81, 35392 Giessen, Germany

2 Instituto de Patología Animal, Facultad de Ciencias Veterinarias, Universidad Austral de Chile, Valdivia, Chile

3 Institute of Anatomy and Cell Biology, Justus Liebig University Giessen, Aulweg 123, 35385 Giessen, Germany sucking lice (Durden and Musser 1994; Leonardi and Palma 2013), which represents a group of permanent, obligate, and wing-free ectoparasitic insects of eutherian mammals exhibiting a hematophagous lifestyle (Kim and Ludwig 1978). Representatives of Echinophthiriidae are of special interest since they are the only sucking lice family which infest host species with semi-aquatic lifestyles, such as Pinnipedia and American river otters (Lontra canadensis) (Murray 1976; Kim 1985; Leonardi and Palma 2013). The host range of the genus Antarctophthirus comprises different pinnipeds including the families Odobenidae, Otariidae, and Phocidae (Leonardi and Palma 2013). Compared with the other six host-specific members within the genus, A. microchir infests a broader range of host species. Thus, findings on this parasite were reported from all six species of the otariid subfamily Otariinae, the sea lions, which show a wide geographical distribution and occur in both hemispheres (Kim et al. 1975; Leonardi and Palma 2013; Leonardi et al. 2014). Previous findings reported on A. microchir from free-ranging South American sea lion (Otaria flavescens) pups from Argentina 
and included re-description (Leonardi et al. 2009), morphological studies (Leonardi et al. 2012a) and numerous publications on biology (Leonardi et al. 2012b; Leonardi and Lazzari 2014), transmission (Leonardi et al. 2013), and population dynamics (Aznar et al. 2009) of this parasite. First description of A. microchir parasitizing $O$. flavescens in Chile was published in 2008 (Crovetto et al. 2008).

The South American sea lion shows a wide geographical occurrence commonly ranging along the Pacific coast of Peru and Chile, the Atlantic coast of Southern Brazil, Uruguay, Argentina, and on the Falkland Islands (Vaz-Ferreira 1982). These polygynous marine mammals live in distinct social structures including harems or bachelor colonies (Cárdenas-Alayza 2017). The Chilean city Valdivia is located approximately $15 \mathrm{~km}$ east of the Pacific Ocean and since the late 1970s this city has been harboring a synanthropic bachelor group of O. flavescens (Schlatter 1976) - a unique "urban" colony of sea lions, which represents the only colony worldwide permanently living in a freshwater habitat. To date, this sea lion colony is composed of approximately 70 individuals between 2 and 15 years of age which still exchange with the Pacific colonies. Their daily presence at the local fish market, a hot-spot of interaction between humans, sea lions, stray dogs, cats, and birds, leads to a remarkable close contact between sea lions and inhabitants or domestic pets within the city of Valdivia. At the same time, this close contact enables transmission of different pathogens. Consistently, a parasitological investigation on the endoparasite fauna of this sea lion colony was carried out and several protozoan and metazoan taxa bearing zoonotic potential [i.e., Cryptosporidium, Giardia, Neobalantidium (former Balantidium; Mathison and Pritt 2019), Diphyllobothriidae gen. sp., Anisakidae gen. sp.) were detected (Hermosilla et al. 2016a).

In past decades, most investigations on echinophthiriid lice required capturing and fixation techniques (Murray and Nicholls 1965; Kim 1972; Kim 1975; Thompson et al. 1998; Mehlhorn et al. 2002; Crovetto et al. 2008; Leonardi et al. 2012b), immobilization applying anesthetic protocols (Murray and Nicholls 1965; Thompson et al. 1998; Dailey et al. 2005; Leonardi et al. 2014, 2016), or even death of free-ranging pinniped host species (Scherf 1963; Murray and Nicholls 1965; Murray et al. 1965; Kim 1972). Furthermore, several investigations were performed during necropsies of found carcasses of $O$. flavescens individuals (Morgades et al. 2006; Gomez-Puerta and Gonzales-Viera 2015).

For the first time, the current study delivers data on the ectoparasite fauna of the synanthropic colony of $O$. flavescens from Valdivia, Chile, by using a self-designed "telescopic lice comb apparatus" for non-invasive lice/nits sample collection. This non-invasive technique is also applicable for future monitoring projects on ectoparasite infestations of other pinniped species [e.g., harbor seals (Phoca vitulina) and gray seals (Halichoerus grypus)] and might serve to acquire a wider range of valuable biological skin material (i.e., hair, dandruffs, epidermal cells/debris, and ectoparasites) without considerable disturbance.

\section{Material and methods}

\section{Study area}

During March and May 2018, an "urban" bachelor group of South American sea lions (O. flavescens) was evaluated within the Chilean city Valdivia for its ectoparasite infestation status. The study area comprised different resting spots of this colony at riverside piers and construction sites $\left(39^{\circ} 48^{\prime}\right.$ $\left.37.566^{\prime \prime} \mathrm{S}, 73^{\circ} 14^{\prime} 49.289^{\prime \prime} \mathrm{W}\right)$, the local fish market ( $39^{\circ}$ $48^{\prime} 46.84^{\prime \prime} \mathrm{S}, 73^{\circ} 14^{\prime} 54.212^{\prime \prime} \mathrm{W}$ ), and a swimming platform $\left(39^{\circ} 48^{\prime} 46.988^{\prime \prime} \mathrm{S}, 73^{\circ} 14^{\prime} 55.24^{\prime \prime} \mathrm{W}\right)$, all being located along or on the freshwater river Calle-Calle within a vicinity of $4 \mathrm{~km}^{2}$.

\section{Non-invasive combing method}

In order to distinguish single individuals of the colony and to create a colony register, animals were observed by eye, individually photographed (Sony Alpha $5100 \AA$, Minato, Japan; Apple iPhone 8 Plus ${ }^{\circledR}$, Cupertino, USA) and filmed by a camera drone (DJI Mavic Pro®, Shenzhen, China). For sample collection, a novel non-invasive combing apparatus was here designed: a metal-toothed lice comb, fabricated for domestic pets (TRIXIE® Heimtierbedarf GmbH \& Co. KG, Tarp, Germany), bolted on an aluminum telescopic rod fixed with tape (TESA $\AA$, Norderstedt, Germany), was used for a broad spectrum of sea lion epidermal material collection (i.e., fur coat hair, lice, nits, and skin tissue samples). The total length of "telescopic lice comb apparatus" was $1.75 \mathrm{~m}$, the metal-teeth row of the comb was $7.5 \mathrm{~cm}$, a single tooth measured $1.5 \mathrm{~cm}$ in length and space between each tooth was $0.5 \mathrm{~mm}$ (Fig. 1).

\section{Sample collection procedure}

For sampling, five non-aggressive sea lions (aged 11 years or older) were chosen on the basis of trustfulness and individual characteristics, i.e., significant skin alterations and apparent pruritus, neoplasia and/or ophthalmic pathologies. When approaching the animals, it was of top priority to radiate a sense of calm and serenity and to maintain direct eye contact with the animals, thereby constantly avoiding frantic movements and loud noises. It appeared beneficial to work from an elevated position or at least to stay at eye-level to the sea lions. Depending on acceptance of individuals to humans, an interspace of at least $0.2-1.5 \mathrm{~m}$ was always kept. After selection of an individual, firstly the telescopic rod was carefully moved into the vision field of the sea lion. Secondly, the sea lion was 


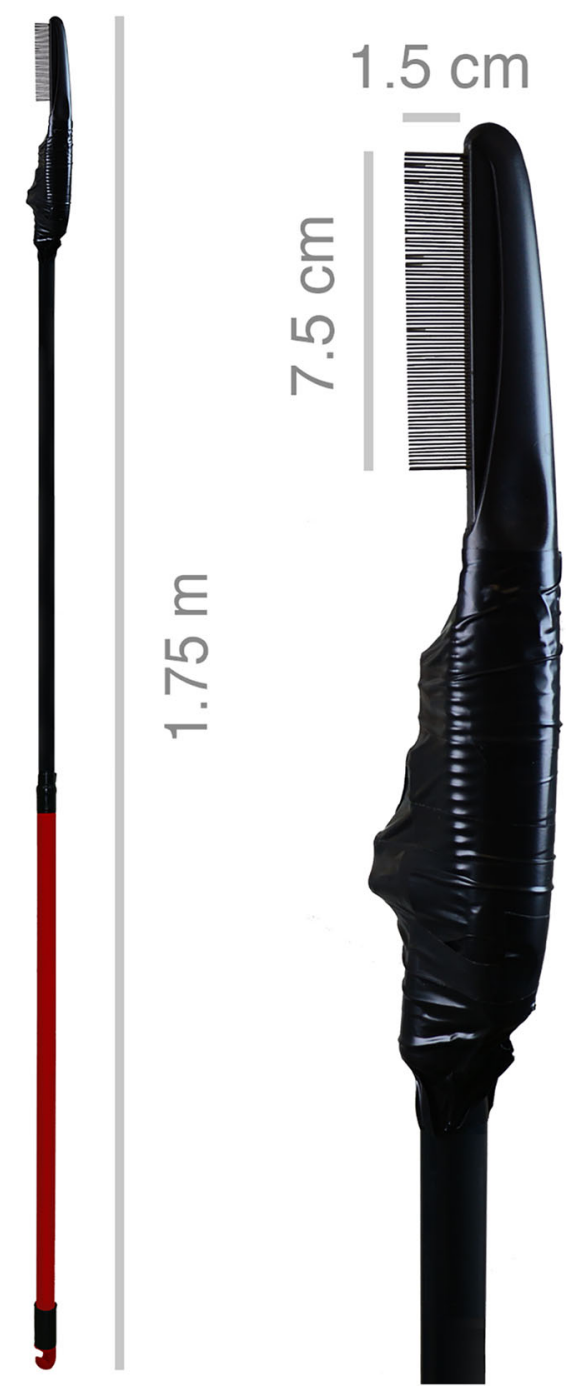

Fig. 1 "Telescopic lice comb apparatus". Overview and close-up of the metal-toothed lice comb on the head of an aluminum telescopic rod fixed with Tesa ${ }^{\circledR}$ tape

allowed to sniff, lick, and explore the combing tool. Then, cautious initial skin contact was made and the individuals were first combed in anterior parts of their body, especially in regions of the head and neck (Fig. 2a-d). In case of acceptance, posterior parts of the body, dorsum, hind flippers, and pelage were also sampled. Reduced hand movements (e.g., showing palm of the hand) and soft-spoken words clearly showed calming effects on sea lions' behavior (see Fig. 2c, d). In addition, interactions were documented with a GoPro Hero $5 \AA$ (San Mateo, USA) camera fixed on a headband (Fig. 3).

Important to note, animals submitted to sampling process were never fed or lured with feed or any other reinforcement auxiliaries. By performing the sampling at open areas near freshwater habitats, the animals always had the chance to leave at any time during the sampling process. Additional video footage of the combing process reveals insights in this special kind of field work (Online Resource 1).

Sea lion sampling was conducted in accordance with the Institutional Ethic Commission of the University Austral of Chile (Chile) and to the Justus Liebig University Giessen (Germany). Permission for sea lion sample collection within the city of Valdivia was extended by the Municipality Service of the city of Valdivia and the Chilean National Service of Fishing and Aquaculture (SERNAPESCA) and in accordance with current Chilean Animal Welfare Legislation.

\section{Storage and morphological identification of $A$. microchir stages}

Sucking lice stages were removed from the lice comb by using dissecting needles and transferred to ziplock bags (please see Fig. 2e and Online Resource 2). Thereafter, specimens were preserved in $70 \%$ ethanol and analyzed using a light microscope (Olympus CX31®, Shinjuku, Japan). For identification, morphological keys for family and genus level (Murray 1976; Kim 1987; Mehlhorn et al. 2002) and morphometric data of A. microchir (Leonardi et al. 2009) were applied.

\section{Scanning electron microscopy}

A female A. microchir preserved in $80 \%$ ethanol was used for scanning electron microscopy (SEM) analysis. Briefly, the specimen was gently deposited on a circular $(10 \mathrm{~mm}$ of diameter) glass coverslips (Nunc) pre-coated with poly-L-lysine (Sigma-Aldrich). Thereafter, the sample was fixed in $2.5 \%$ glutaraldehyde (Merck), post-fixed in $1 \%$ osmium tetroxide (Merck), washed in distilled water, dehydrated, dried by $\mathrm{CO}_{2}$ treatment, and afterwards sputtered with gold (Villagra-Blanco et al. 2017). The sample was examined by using a Philips XL30® (Amsterdam, Netherlands) scanning microscope equipped with a digital camera allocated at the Institute of Anatomy and Cell Biology (Justus Liebig University Giessen, Germany).

\section{Results}

\section{Non-invasive combing procedure and microhabitats of $A$. microchir on $O$. flavescens body surface}

Starting the combing process at anterior parts of the body, including the forehead, dorsal, and ventral areas of the neck, was necessary to obtain the sea lion's confidence. All other body areas were studied after cautious skin contact and a phase of familiarization at cranial body parts. Considering this chronological order, selected sea lions tolerated the combing procedure very well and accepted human presence in the 
Fig. 2 Sampling of the synanthropic $O$. flavescens colony within the city of Valdivia. a, b Sampling from a boat while the sea lion is resting on a swimming platform on the river of Calle-Calle in front of the local fish market. c, d Sampling at a typical resting place of $O$. flavescens in Valdivia. e Lice comb after combing process, item full of hair, and skin tissue; in the background: dissection needle and ziplock bag for sample storage
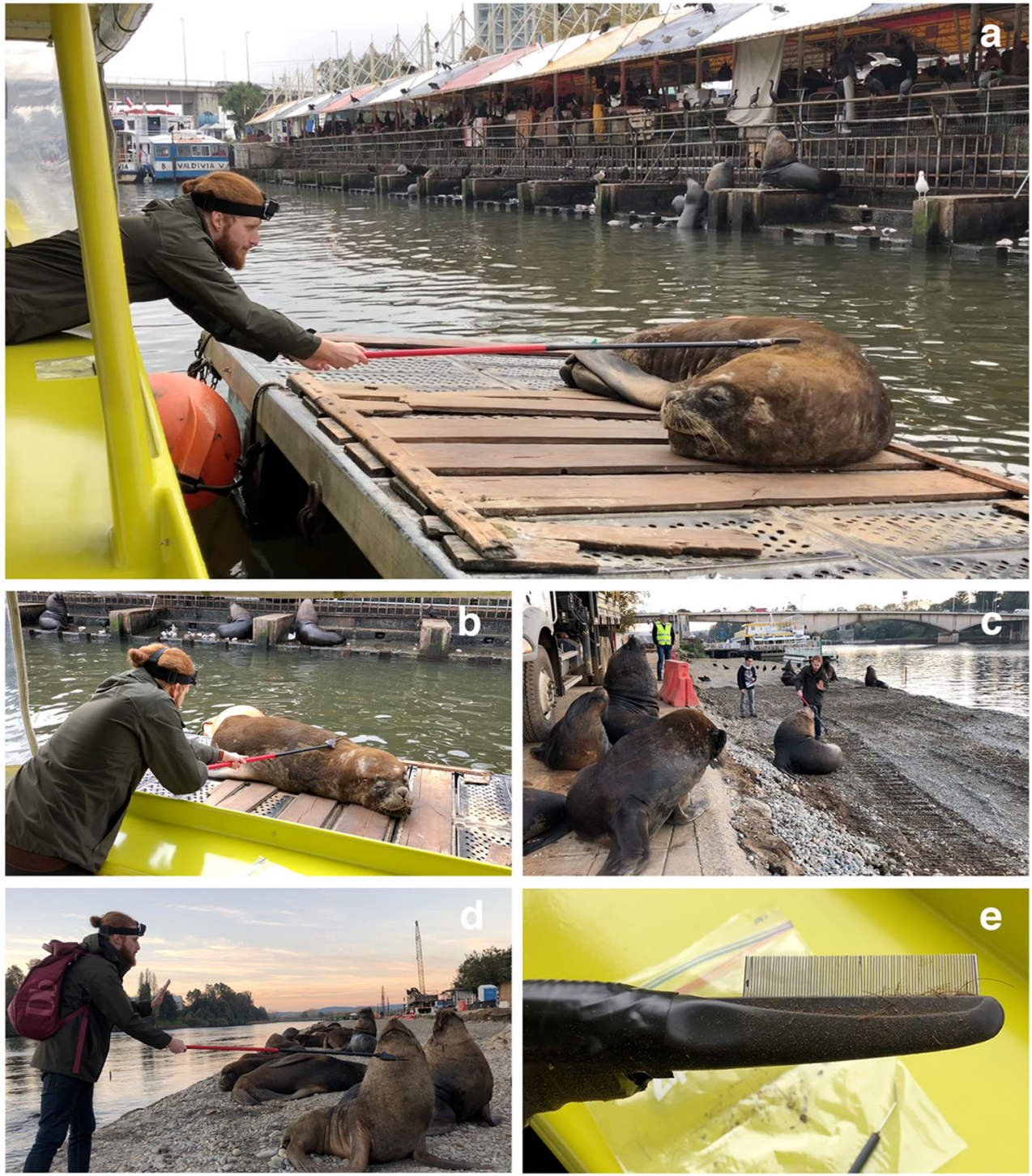

middle of the colony (Fig. 2c, d). Recurrent defensive behavior hardly occurred during sampling. Due to natural shyness, younger animals could not be included in the sampling process. The total combing time (i.e., entire body, anterior, and
Fig. 3 GoPro view: area selection during sampling process on a swimming platform. a

Application of the "telescopic lice comb apparatus". b Starting point of sampling process: anterior parts of the body to gain sea lion's trust. c Consecutive sampling area: posterior parts of the body. d Curious members of the "urban" sea lion colony watching the examination. e Local fish market in the background with numerous sea lions waiting for fish waste

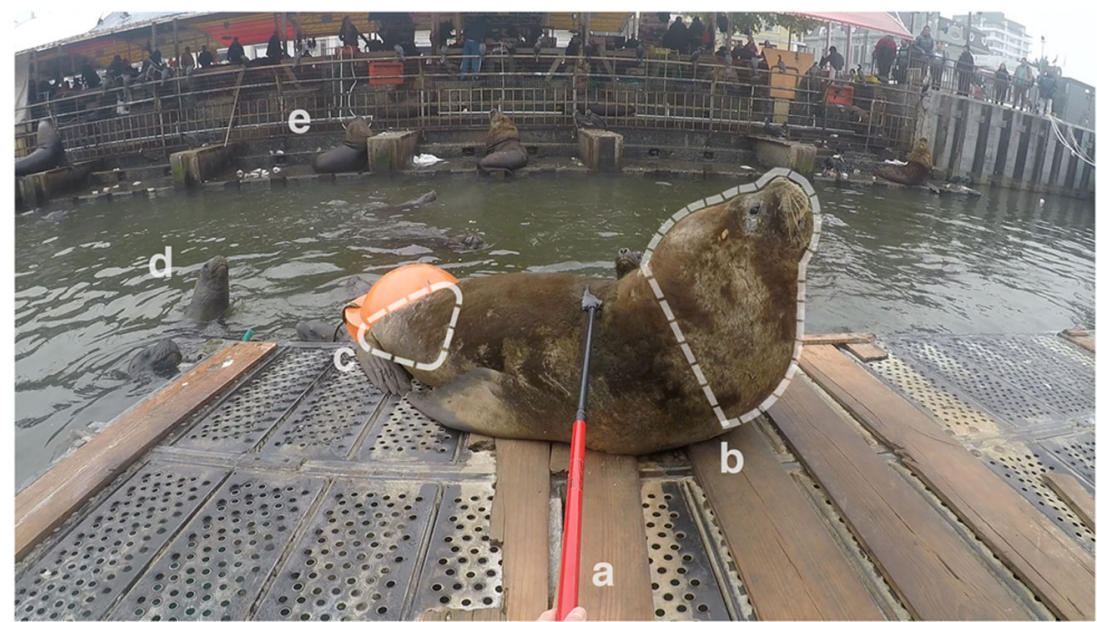


posterior parts) varied between individuals and encompassed between 15 and $45 \mathrm{~min} /$ individual and examination. Five sampled sea lions showed clear satisfaction while being combed thereby extending their heads or necks, changing position towards to telescope in order to accommodate certain areas of pruritus to the comb devise (please refer to Online Resource 1).

Overall, all A. microchir stages were detected at the caudal back of the animals, especially at the junction between the back and the hind flippers (Fig. 3). The secondstage larva was located near the flank, slightly more ventral than the other stages. No stages of $A$. microchir were found at cranial parts of sea lion's body even though skin lesions were also apparent at these areas. Collected skin samples consisted of hair, dandruffs, epidermal debris, and ectoparasite stages.

\section{Infestation with $A$. microchir}

Evaluation of the ectoparasite status of this synanthropic colony revealed a patent infestation with the echinophthiriid louse $A$. microchir in $80 \%$ (4/5) of $O$. flavescens individuals. In total, nine adult $A$. microchir stages (three females and six males), 1 second-stage larva and three nits of $A$. microchir have been detected (Fig. 4). The presence of all these different stages proved that the entire lifecycle was completed on the animals despite residing in a freshwater habitat and in the absence of females and pups. No other ectoparasite species were here identified.

\section{Microscopical findings}

Light microscopic examination of different stages (Fig. 4) and SEM analysis of a female specimen (Fig. 5a, b) allowed morphological species identification of $A$. microchir according to literature (Enderlein 1906; Leonardi et al. 2009). The head of A. microchir was eyeless (Fig. 5a) and carried thick antennae on both lateral sides. In adult lice, the antennae were composed of five tapering segments (Fig. 4c, d), while the second-stage larva showed antennae with four segments (Fig. 4b). The genital opening of the female stage was laterally bordered with two clusters of hairs, which consisted of long and slightly modified setae (Fig. 5b). Abdominal segments were coated with overlapping scales, which showed a typical flat, oval, and leaf-like shape (Fig. 5b). Spines exhibited a typical elongated shape with a tapering end and could clearly be distinguished from scales (Fig. 5b). Nomenclature of setae was guided by the description of Kim and Ludwig (1978) and additionally according to the revised taxonomy published by Mehlhorn et al. (2002) and Leonardi et al. (2009).

\section{Discussion}

Overall, ectoparasite studies on A. microchir in free-ranging South American sea lions generally focused so far on pups due to easier handling while capturing and fixation (Leonardi et al. 2012b; Leonardi 2014), whereas knowledge on infestation status of adult individuals, especially males is still very
Fig. 4 Light microscopic images of different stages of A. microchir. a Nit. b Second-stage larva. c Adult male. d Adult female. Scale bars, $500 \mu \mathrm{m}$
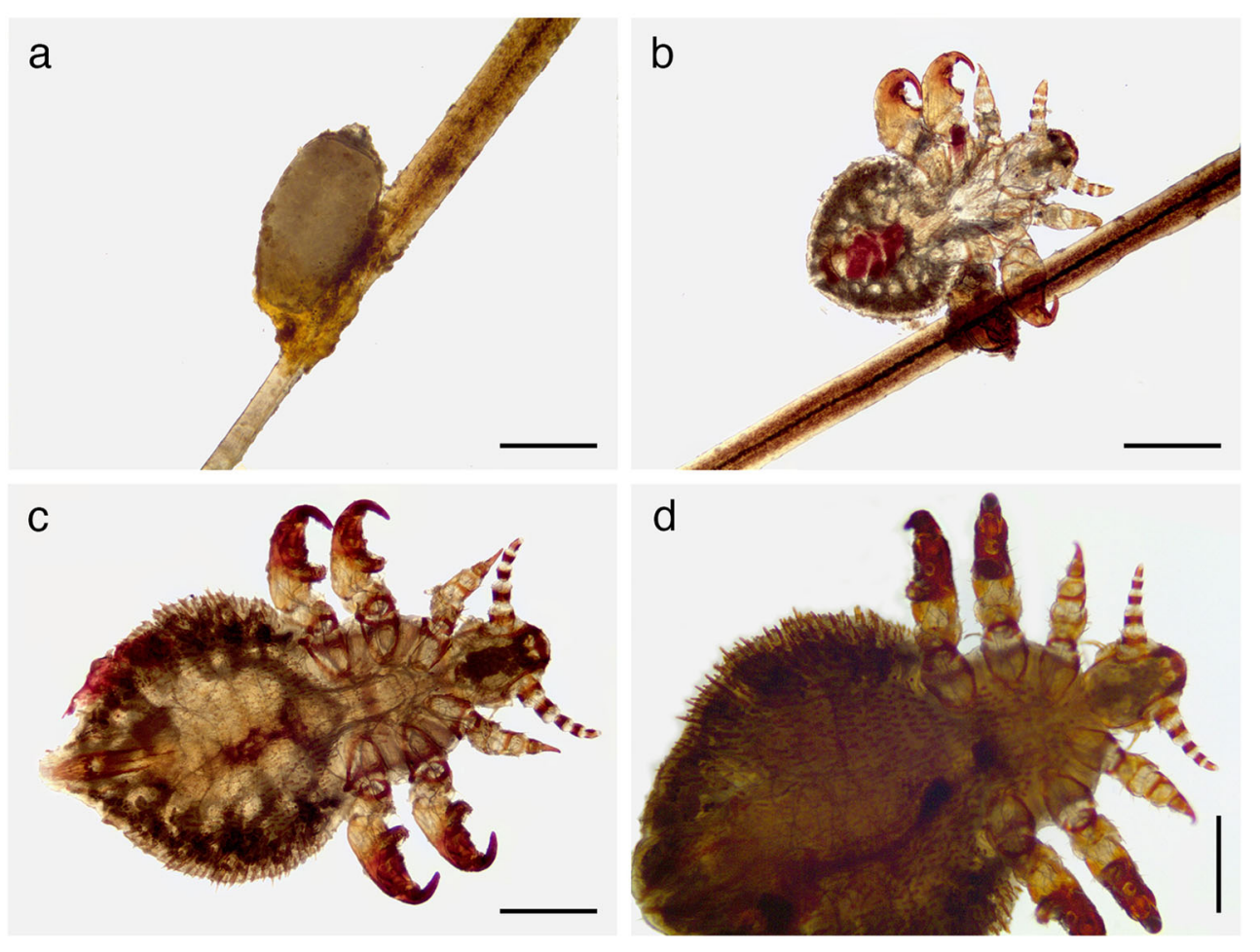
Fig. 5 Scanning electron microscopic images of an adult female of A. microchir. View of a eyeless head and fivefold segmented antennae, b female genital porus surrounded by clusters of hairs (ha), leaf-like shaped scales (sc), and spines (sp). Scale bars, $100 \mu \mathrm{m}$
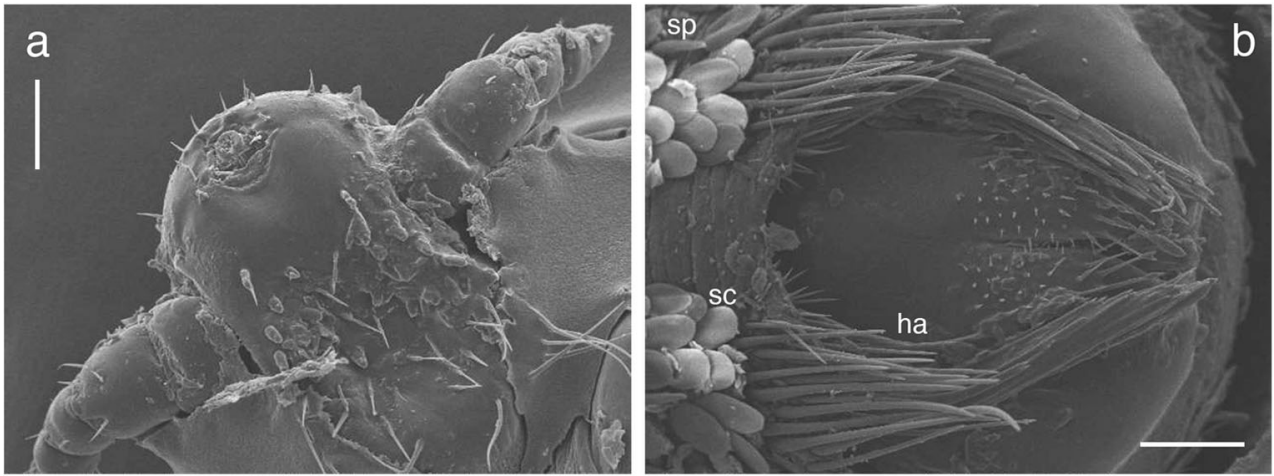

little (Crovetto et al. 2008). To our best knowledge, the ectoparasite infestation status of free-ranging bachelor colonies of $O$. flavescens has never been examined before.

Taking advantage from a striking adaptation of this "urban" colony of South American sea lions to human activities, we here developed a "telescopic lice comb apparatus" allowing for skin sampling of adult sea lions in a non-invasive and stress reduced way. By obtaining biological material of pinnipeds, e.g., hair (including roots), skin tissue samples (e.g., dandruffs), and different parasite stages, this method opens a broad spectrum of new research fields and could support future projects, including endocrinological (Koren et al. 2002; Sheriff et al. 2011), toxicological (Castellini et al. 2012; McHuron et al. 2012; Peterson et al. 2016), and even molecular genetic analyses of sampled animals. Moreover, this method allows not only unmolested sample collections, but also offers security measures by guaranteeing a certain interspace between researchers and animals. The non-invasive aspect of this method was also reflected by the choice of sampling spots. As such, each animal could interrupt examination and leave at any time the combing process. Since many individuals of this colony were cluttered with skin lesions (e.g., alopecia, hyperkeratosis, pruritus), which could also be caused by bacterial or fungal infections, most animals cooperated very well and even seemed to enjoy the treatment due to pruritus relief. This impression was strengthened by the duration of the combing process, which lasted up to $45 \mathrm{~min}$ per individual.

However, despite their excellent adjustment to a life in the city, it has to be kept in mind that the current synanthropic sea lion population still represents wild and free-ranging animals (Schlatter 1976) and younger individuals can still migrate to the Pacific colonies at reproductive ages. Consequently, the sampling process delivers a smaller amount of biological material and is more time consuming than examination of fixed animals (Leonardi 2014) or during necropsies. However, in today's world, where anthropogenic pressure influences and determines wildlife as intensive as never before, non-invasive or minimally invasive methods should constitute indispensable tools in research of marine mammals (Gales et al. 2009), and it is in our responsibility to develop creative, protecting methods for obtaining a broad range of biological material (Kleinertz et al. 2014; Hermosilla et al. 2015, 2016a, b, 2018a, b).

Morphological characteristics of A. microchir were intensively studied in the past, and the morphological identification of the current specimen was in accordance with published determination keys (Enderlein 1906; Murray 1976; Kim 1987; Mehlhorn et al. 2002), the re-description (Leonardi et al. 2009), and SEM examination of this species (Leonardi et al. 2012a).

Regarding predilection sites of the genus Antarctophthirus, Kim (1975) reported eyelids, hips, hind flippers, and tail as main body sites of sucking lice. However, Leonardi et al. (2012b) failed to detect $A$. microchir on hind flippers of pups and mainly found them on the back and the belly. Important to note, due to fixation, anterior parts of pup bodies were not examined (Leonardi et al. 2012b). Another study reported A. microchir to infest the basis of the snout (Crovetto et al. 2008). In contrast to other monoxenous lice genera, Antarctophthirus infests a wide range of host species, involving eared seals (Otariidae), walruses (Odobenidae), and earless seals (Phocidae) (Leonardi and Palma 2013), which may all differ in their mode of locomotion, pelage, and geographical distribution (Leonardi et al. 2012b). As already described for the closely related chewing lice of chicken (Johnson et al. 2012), it was discussed that Antarctophthirus infestation of certain areas of hosts may represent a microhabitat selection. Enderlein (1906) suggested that in contrast to Echinophthirius spp., which are characterized by the absence of scales and mainly infest areas of seals head, the presence of scales in case of Antarctophthirus spp. could be essential for lice breathing activities in case that parts of the body related to respiration (e.g., head, snout) would not be infested. Consistently, in the current study all stages of $A$. microchir were found in posterior parts of the body, especially at caudal parts of the back close to the junction to the hind flippers accordingly to Kim (1975).

Different echinophtiriid lice transmission routes have been reported, whereby all of them can only occur if the pinniped host is ashore (Kim 1975). In case of Proechinophthirus fluctus and A. callorhini, parasitizing the Northern fur seal (Callorhinus ursinus), Kim (1972) proposed direct 
transmission from cows to pups, especially in first hours after parturition, as the major pathway of transmission. Pup-to-pup transmission of lice may also play a pivotal role, particularly in crowded colonies (Kim 1975). In contrast, horizontal transmission between cows and bulls was described as unlikely due to low lice densities on adult seals (Kim 1975). Indirect transmission through lice/larval stages that have fallen from hosts have not been described so far but might occur as this transmission route is well-known for closely terrestrial lice genera (e.g., Haematopinus, Pediculus). In line to direct transmission, cow-to-pup transmission was also confirmed as main transmission route for A. microchir under natural conditions (Aznar et al. 2009; Leonardi et al. 2013). Early stages of A. microchir, i.e., eggs and first larval stages, were reported to mainly occur on pups, which avoid water contact during their first weeks of life (Leonardi and Lazzari 2014). Consistently, in vitro experiments revealed that these lice stages poorly tolerated periods underwater (Leonardi and Lazzari 2014), which is in accordance with weak water resistance of eggs revealed in other studies on echinophtiriid lice (Murray and Nicholls 1965). However, in contrast to firststage larvae, later larval stages and adults of A. microchir tolerate periods of submersion (Leonardi and Lazzari 2014). Interestingly, the synanthropic $O$. flavescens population in Valdivia exclusively consisted of male individuals, with the youngest members being aged approximately 2 years. The fact that nits, second-stage larva, and adult lice (females and males) were detected on these animals, proves that A. microchir is capable to fulfill the entire life cycle within this bachelor group even in the absence of pups, yearlings, or females. The ever-granted availability of fish at the local market may shorten or even occasionally cut the hunting periods of these animals thereby resulting in extended periods ashore. Based on the distinct social behaviors of this synanthropic bachelor group, the animals exhibit longer circadian resting periods on platforms, riverside piers, and around the local fish market lying in close contact to each other, which might increase the chance of horizontal lice transmission. Overall, the current data indicate that adult $O$. flavescens males might play a role as reservoir hosts for A. microchir even in coastal habitats, where gatherings of bachelor males mainly occur at the borders of the colonies (Cárdenas-Alayza 2017).

This report delivers first insights in A. microchir infestation of a synanthropic colony of South American sea lion (O. flavescens) males living and evidencing that A. microchir is capable to fulfill its life cycle in a freshwater habitat. However, the knowledge on A. microchir-borne diseases in free-living adult sea lions is still little and will be expanded in the near future. In the current study, the usefulness of our non-invasive combing method was clearly demonstrated and will allow sampling of biological material (e.g., hair, epithelial cells) from pinnipeds for a broad spectrum of other investigations.
Acknowledgments We would like to gratefully thank Rafael Burgos (Institute of Pharmacology), Enrique Paredes (Institute of Pathology), and Javier Painean Peña (Institute of Parasitology) for the great assistance at the Universidad Austral de Chile, Valdivia, Chile. Further we are thankful to Esteban Reyes Lobao-Tello and Sandra Azócar for their kind help during field studies as well as the Municipality Service of the city of Valdivia and SERNAPESCA for permission to enter and collect samples at construction areas.

Funding This study was funded by the Institute of Parasitology (Justus Liebig University Giessen) and the Institute of Pathology (Universidad Austral de Chile).

\section{Compliance with ethical standards}

Sea lion sampling was conducted in accordance with the Institutional Ethic Commission of the University Austral of Chile (Chile) and to the Justus Liebig University Giessen (Germany). Permission for sea lion sample collection within the city of Valdivia was extended by the Municipality Service of the city of Valdivia and the Chilean National Service of Fishing and Aquaculture (SERNAPESCA) and in accordance with current Chilean Animal Welfare Legislation.

Conflict of interest The authors declare that they have no conflict of interest.

Open Access This article is distributed under the terms of the Creative Commons Attribution 4.0 International License (http:// creativecommons.org/licenses/by/4.0/), which permits unrestricted use, distribution, and reproduction in any medium, provided you give appropriate credit to the original author(s) and the source, provide a link to the Creative Commons license, and indicate if changes were made.

\section{References}

Aznar FJ, Leonardi MS, Berón Vera B, Vales DG, Ameghino S, Raga JA, Crespo EA (2009) Population dynamics of Antarctophthirus microchir (Anoplura : Echinophthiriidae) in pups from South American sea lion, Otaria flavescens, in Northern Patagonia. Parasitology 136:293-303

Cárdenas-Alayza S (2017) South American sea lion (Otaria byronia). In: Würsig B, Thewissen JGM, Kovacs KM (eds) Encyclopedia of marine mammals, Third edn. Academic Press, San Diego, pp 907910

Castellini JM, Rea LD, Lieske CL, Beckmen KB, Fadely BS, Maniscalco JM, O'Hara TM (2012) Mercury concentrations in hair from neonatal and juvenile Steller sea lions (Eumetopias jubatus): implications based on age and region in this Northern Pacific marine sentinel piscivore. EcoHealth 9:267-277

Crovetto A, Franjola R, Silva R (2008) Primer registro en Chile de Antarctophthirus microchir (Anoplura) en lobo marino común (Otaria flavescens) (In Spanish). Arch Med Vet 40:305-308

Dailey M, Ellin R, Parás A (2005) First report of parasites from pinnipeds in the Galapagos Islands, Ecuador, with a description of a new species of Philophthalmus (Digenea: Philophthalmidae). J Parasitol 91:614-617

Durden LA, Musser GG (1994) The sucking lice (Insecta, Anoplura) of the world: a taxonomic checklist with records of mammalian hosts and geographical distributions. Bull Am Mus Nat Hist 218:1-90 
Enderlein G (1906) Läusestudien. V. Schuppen als sekundäre Atmungsorgane, sowie über eine neue antarktische Echinophthiriiden-Gattung (In German). Zool Anz 29:659-665

Gales NJ, Bowen WD, Johnston DW, Kovacs KM, Littnan CL, Perrin WF, Reynolds JE III, Thompson PM (2009) Guidelines for the treatment of marine mammals in field research. Mar Mammal Sci 25: 725-736

Gomez-Puerta LA, Gonzales-Viera O (2015) Ectoparásitos del lobo marino sudamericano (Otaria flavescens) de la costa peruana (In Spanish). Rev Peru Biol 22:259-262

Hermosilla C, Silva LMR, Prieto R, Kleinertz S, Taubert A, Silva MA (2015) Endo- and ectoparasites of large whales (Cetartiodactyla: Balaenopteridae, Physeteridae): overcoming difficulties in obtaining appropriate samples by non-and minimally-invasive methods. Int J Parasitol Parasites Wildl 4:414-420

Hermosilla C, Silva LMR, Navarro M, Taubert A (2016a) Anthropozoonotic endoparasites in free-ranging (urban) South American sea lions (Otaria flavescens). J Vet Med 2016:1-7. https://doi.org/10.1155/2016/7507145

Hermosilla C, Silva LMR, Kleinertz S, Prieto R, Silva MA, Taubert A (2016b) Endoparasite survey of free-swimming baleen whales (Balaenoptera musculus, B. physalus, B. borealis) and sperm whales (Physeter macrocephalus) using non/minimally invasive methods. Parasitol Res 115:889-896

Hermosilla C, Hirzmann J, Silva LMR, Brotons JM, Cerdà M, PrengerBerninghoff E, Ewers C, Taubert A (2018a) Occurrence of anthropozoonotic parasitic infections and faecal microbes in freeranging sperm whales (Physeter macrocephalus) from the Mediterranean Sea. Parasitol Res 117:2531-2541

Hermosilla C, Hirzmann J, Silva LMR, Scheufen S, Prenger-Berninghoff E, Ewers C, Häussermann V, Försterra G, Poppert S, Taubert A (2018b) Gastrointestinal parasites and bacteria in free-living South American sea lions (Otaria flavescens) in Chilean Comau Fjord and new host record of a Diphyllobothrium scoticum-like cestode. Front Mar Sci 5:459

Johnson KP, Shreve SM, Smith VS (2012) Repeated adaptive divergence of microhabitat specialization in avian feather lice. BMC Biol 10:52

Kim KC (1972) Louse populations of the northern fur seal (Callorhinus ursinus). Am J Vet Res 33:2027-2036

Kim KC (1975) Ecological and morphological adaption of the sucking lice (Anoplura, Echinophthiriidae) on the northern fur seal. Rap Process 169:504-515

Kim KC (1985) Coevolution of parasitic arthropods and mammals. Wiley, New York

Kim KC (1987) Order Anoplura. In: Stehr FW (ed) Immature insects. Kendal/Hunt Publishing Company, Dubuque, pp 224-245

Kim KC, Ludwig HW (1978) The family classification of the Anoplura. Syst Entomol 3:249-284

Kim KC, Repenning CA, Morejohn GV (1975) Specific antiquity of the sucking lice and evolution of otariid seals. Rap Proces 169: 544-549

Kleinertz S, Hermosilla C, Ziltener A, Kreicker S, Hirzmann J, AbdelGhaffar F, Taubert A (2014) Gastrointestinal parasites of free-living Indo-Pacific bottlenose dolphins (Tursiops aduncus) in the Northern Red Sea, Egypt. Parasitol Res 113:1405-1415

Koren L, Mokady O, Karaskov T, Klein J, Koren G, Geffen E (2002) A novel method using hair for determining hormonal levels in wildlife. Anim Behav 63:403-406

Leonardi MS (2014) Faster the better: a reliable technique to sample anopluran lice in large hosts. Parasitol Res 113:2015-2018

Leonardi MS, Lazzari CR (2014) Uncovering deep mysteries: the underwater life of an amphibious louse. J Insect Physiol 71:164-169
Leonardi MS, Palma RL (2013) Review of the systematics, biology and ecology of lice from pinnipeds and river otters (Insecta: Phthiraptera: Anoplura: Echinophthiriidae). Zootaxa 3630:445-466

Leonardi MS, Crespo EA, Raga JA, Fernández M (2009) Redescription of Antarctophthirus microchir (Anoplura: Echinophthiriidae) from the South American sea lion, Otaria flavescens, from Patagonia, Argentina. J Parasitol 95:1086-1092

Leonardi MS, Crespo EA, Raga JA, Fernández M (2012a) Scanning electron microscopy of Antarctophthirus microchir (Phthiraptera: Anoplura: Echinophthiriidae): studying morphological adaptations to aquatic life. Micron 43:929-936

Leonardi MS, Crespo EA, Vales DG, Feijoo M, Raga JA, Aznar FJ (2012b) Life begins when the sea lion is ashore: microhabitat use by a louse living on a diving mammal host. Bull Entomol Res 102:444-452

Leonardi MS, Crespo EA, Raga JA, Aznar FJ (2013) Lousy mums: patterns of vertical transmission of an amphibious louse. Parasitol Res 112:3315-3323

Leonardi MS, Poljak S, Carlini P, Galliari J, Bobinac M, Santos M, Márquez ME, Negrete J (2014) Antarctophthirus carlinii (Anoplura: Echinophthiriidae), a new species from the Weddell seal Leptonychotes weddelli. Parasitol Res 113:3947-3951

Leonardi MS, Bobinac M, Negrete J (2016) Redescription of Antarctophthirus lobodontis (Anoplura: Echinophthiriidae) from the crabeater seal and identification key for Antarctic lice. Polar Biol 39:671-676

Mathison BA, Pritt BS (2019) Medical parasitology taxonomy update, 2016-2017. J Clin Microbiol 57:e01067-18

McHuron EA, Harvey JT, Castellini JM, O’Hara TM (2012) Hair sampling location in harbor seals (Phoca vitulina) affects selenium and mercury concentrations: implications for study design of trace element determination in pinnipeds. Mar Pollut Bull 64:2519-2522

Mehlhorn B, Mehlhorn H, Plötz J (2002) Light and scanning electron microscopical study on Antarctophthirus ogmorhini lice from the Antarctic seal Leptonychotes weddellii. Parasitol Res 88:651-660

Morgades D, Katz H, Castro O, Capellino D, Casas L, Benítez G, Venzal JM, Moraña A (2006) Fauna parasitaria del lobo fino Arctocephalus australis y del león marino Otaria flavescens (Mammalia, Otariidae) en la costa uruguaya (In Spanish). In: Menafra R, RodríguezGallego L, Scarabino F, Conde D (eds) Bases para la conservación y el manejo de la costa uruguaya. Vida Silvestre Uruguay, Montevideo, pp 89-96

Murray MD (1976) Insect parasites of marine birds and mammals. In: Cheng L (ed) Marine insects. North-Holland Publishing, Amsterdam, pp 79-96

Murray MD, Nicholls DG (1965) Studies on the ectoparasites of seals and penguins. I. The ecology of the louse Lepidophthirus macrorhini Enderlein on the southern elephant seal, Mirounga leonina (L). Aust J Zool 13:437-454

Murray MD, Smith MSR, Soucek Z (1965) Studies on the ectoparasites of seals and penguins. II. The ecology of the louse Antarctophthirus ogmorhini Enderlein on the Weddell seal, Leptonychotes weddelli Lesson. Aus J Zool 13:761-772

Peterson SH, McHuron EA, Kennedy SN, Ackerman JT, Rea LD, Castellini JM, O'Hara TM, Costa DP (2016) Evaluating hair as a predictor of blood mercury: the influence of ontogenetic phase and life history in pinnipeds. Arch Environ Contam Toxicol 70:28-45

Scherf H (1963) Ein Beitrag zur Kenntnis zweier Pinnipedierläuse (Antarctophthirus trichechi Boheman und Echinophthirius horridus Olfers) (In German). Z Parasitenk 23:16-44

Schlatter RP (1976) Penetración del lobo marino común, Otaria flavescens Shaw, en el Río Valdivia y afluentes (In Spanish). Medio Amb 2:86-90 
Sheriff MJ, Dantzer B, Delehanty B, Palme R, Boonstra R (2011) Measuring stress in wildlife: techniques for quantifying glucocorticoids. Oecologia 166:869-887

Thompson PM, Corpe HM, Reid RJ (1998) Prevalence and intensity of the ectoparasite Echinophthirius horridus on harbour seals (Phoca vitulina): effects of host age and inter-annual variability in host food availability. Parasitology 117:393-403

Vaz-Ferreira R (1982) Otaria flavescens (Shaw), South American sea lion. In: FAO, UNEP (ed) Mammals in the seas. Vol IV. Small cetaceans, seals, sirenians and otters. FAO Fisheries series, Rome pp 477-495
Villagra-Blanco R, Silva LMR, Muñoz-Caro T, Yang Z, Li J, Gärtner U, Taubert A, Zhang X, Hermosilla C (2017) Bovine polymorphonuclear neutrophils cast neutrophil extracellular traps against the abortive parasite Neospora caninum. Front Immunol 8:606

Publisher's note Springer Nature remains neutral with regard to jurisdictional claims in published maps and institutional affiliations. 